\title{
Genetic diversity and transmission patterns of Echinococcus granulosus sensu stricto among domestic ungulates of Sardinia, Italy
}

\author{
Naunain Mehmood ${ }^{1} \cdot$ Giorgia Dessì $^{2} \cdot$ Fahad Ahmed $^{2} \cdot$ Gaelle Joanny $^{2} \cdot$ Claudia Tamponi $^{2} \cdot$ Maria Grazia Cappai $^{2}$. \\ Antonio Varcasia ${ }^{2}\left[\right.$. Antonio Scala ${ }^{2}$
}

Received: 15 November 2020 / Accepted: 5 May 2021 / Published online: 19 June 2021

(c) The Author(s) 2021

\begin{abstract}
Cystic echinococcosis (CE), a parasitic zoonosis of public health and economic concern, is highly endemic in Sardinia, Italy. The study involved examining the intraspecific variability and demographic structure of Echinococcus granulosus sensu stricto (s.s.) in common hosts of this parasite. Molecular surveillance included the fragment amplification of a partial mitochondrial gene, $\operatorname{coxl}(750 \mathrm{bp})$, for a total of 69 isolates derived from sheep $(n=52)$, cattle $(n=11)$, pigs $(n=4)$, and goats $(n=2)$. It was ascertained that $E$. granulosus s.s. was the primary agent of infection among these ungulates and G1 genotype was highly prevalent $(79.71 \%$ ). Considerable intraspecific variation was found, revealing the existence of 22 haplotypes with relatively high haplotype $(0.8555 \pm 0.033)$ and low nucleotide diversities $(0.00281 \pm 0.00030)$. Population demographics indicated an expanding parasitic population signifying negative deviation from neutrality indices. Little genetic differentiation was found between the subpopulations of E. granulosus s.s. in the island. Moreover, the geographic dispersal of genotypes G1 and G3 also indicated similarity between Sardinian and mainland Echinococcus granulosus s.s. populations reaffirming the sympatric occurrence and efficient transmission of G1 and G3 genotypes. Molecular survey of CE has the potential to yield baseline information on the infective genotypes among the intermediate hosts and helps in devising suitable control strategies for curtailing the disease.
\end{abstract}

Keywords Cystic echinococcosis $\cdot$ Echinococcus granulosus s.s. $\cdot$ Genetic diversity $\cdot$ Haplotypes $\cdot$ Sardinia

\section{Introduction}

Cystic echinococcosis (CE) is a globally widespread zoonosis caused by the larval stages of a tapeworm Echinococcus granulosus sensu lato (s.l.). It is listed among

Section Editor: Bruno Gottstein

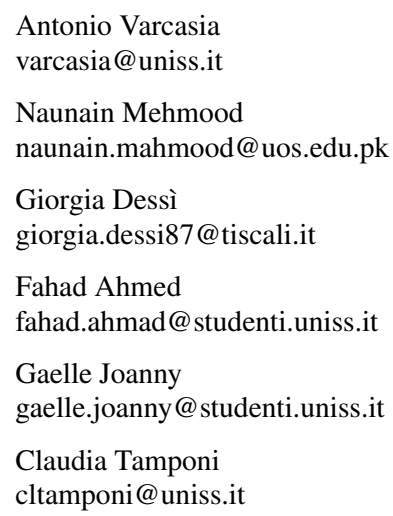

WHO-neglected diseases for which control strategies are suggested (Romig et al. 2015). Dogs and wild canids are usually the definitive hosts which harbor the adult stages of this parasite. Eggs are shed in feces of the definitive host and dispersed in the environment, where they can be picked up by a wide range of intermediate hosts and humans where the eggs can develop to larval stage

Maria Grazia Cappai

mgcappai@uniss.it

Antonio Scala

scala@uniss.it

1 Department of Zoology, University of Sargodha, Sargodha, Pakistan

2 Dipartimento Di Medicina Veterinaria, Università Degli Studi Di Sassari, Via Vienna, 2, 07100 Sassari, Italy 
(metacestode) forming hydatid cysts in internal organs and cause CE (Deplazes et al. 2017; Thompson 2017). Globally, CE is of major health significance due to indirect revenue losses incurred from human morbidity and mortality and direct economic losses to livestock industry because of offal condemnation (Eckert and Deplazes 2004; Budke et al. 2006; Battelli 2009).

Taxonomy of the genus Echinococcus has remained a challenging issue for decades due to striking intraspecific genetic diversity, morphology, life cycle, and host range differences (Romig et al. 2015). Thus, the taxonomy of this cryptic species complex has experienced perpetual revisions on the basis of adult morphological traits and genetic studies involving mitochondrial and nuclear genomes (Saarma et al. 2009; Nakao et al. 2013). Initial strain description based on intraspecific variability at mitochondrial level was provided by Bowles et al. (1992). Subsequent studies, relying on the partial and complete mitogenome analysis and nuclear genomic studies, aimed to clarify the species composition within E. granulosus sensu lato. Current species now include the most common E. granulosus sensu stricto (G1 and G3 genotypes), Echinococcus equinus (G4 genotype), Echinococcus ortleppi (G5 genotype), Echinococcus canadensis (G6-G10 genotypes), and Echinococcus felidis (lion strain). The taxonomic status of genotypes G6/G7 and G8/G10 is still under dispute (Nakao et al. 2015; Romig et al. 2015; Laurimäe et al. 2018). Genotype G2, which was initially regarded as a distinct genotype (Bowles et al. 1992), was recently established to be a part of G3 (Kinkar et al. 2017). Therefore, G3 may be underrepresented due to erroneous allocation of CE cases to G2 (Kinkar et al. 2018a). Furthermore, G3 genotype, which was initially suggested to be buffalo specific (Bowles et al. 1992), was subsequently identified in multiple intermediate hosts like sheep, cattle, goats, camels, and wild boars implying the transmission potential of G3 beyond buffalo (Sharbatkhori et al. 2011; Laurimäe et al. 2019; Mehmood et al. 2020). Relatively high prevalence of the G3 strain is being recorded in Italy and Sardinia compared to other European and Mediterranean countries indicating its spread beyond the Indian region (Capuano et al. 2006; Busi et al. 2007; Kinkar et al. 2018a).

In Italy, CE is widespread and present in Sardinia (Varcasia et al. 2020). Sardinia is the second largest Mediterranean island and hosts more than $40 \%$ of the entire national sheep stock (Conchedda et al. 2010). Studies on the intermediate hosts have revealed very high rate of infection in sheep ranging between $65.3 \%$ (Varcasia et al. 2020) and 75\% (Scala et al. 2006) followed by cattle (41.5\%), pigs (9.4\%; Varcasia et al. 2006), and wild boars (3.7\%; Varcasia et al. 2008). Among the prevalent species of the parasite, E. granulosus s.s. is the most widespread species of the complex found in all intermediate hosts (Varcasia et al. 2006). Previously, E. equinus and E. canadensis (G7 genotype) have been reported from the horses and pigs in Sardinia (Varcasia et al. $2006,2008)$. Therefore, it is highly needed to understand the transmission patterns and regional segregation of E. granulosus s.s. in all intermediate hosts with special attention to endemic diffusion of CE in Sardinia. Thus, the current study aimed at molecular screening of E. granulosus s.s. from the different intermediate hosts (sheep, cattle, pigs, and goats) for appropriately estimating the prevalence of infective genotypes and their correct allocation on the basis of partial mitochondrial coxl marker. Moreover, the population structure analysis of E. granulosus s.s. genotypes circulating among animal hosts in Sardinia was also undertaken to highlight genetic and demographic patterns.

\section{Material and methods}

A total of 70 hydatid cyst specimens were collected from the sheep $(n=52)$, cattle $(n=11)$, pigs $(n=4)$, and goats $(n=3)$ during routine meat inspection in different municipalities of Sardinia from 2012 to 2018. Cyst presence in the visceral organs was analyzed by visual inspection and palpation. Infested organs (liver/lungs) were transported to the laboratory of Parasitology and Parasitic Diseases, Veterinary Teaching Hospital, University of Sassari, for further processing.

DNA was extracted from either germinal layer or protoscoleces using a commercial DNA extraction kit (Roche Diagnostics, USA) following the instruction manual. DNA concentration was assessed by a NanoDrop ${ }^{\mathrm{TM}}$ Lite spectrophotometer (Thermo Fisher Scientific, MA). PCR amplification for the partial mitochondrial gene, coxl, was done using primer pairs described by Nakao et al. (2000). Purified PCR products were sent for bidirectional sequencing in both forward and reverse directions (ABI Prism 3100 Genetic Analyzer, Applied Biosystems).

All sequenced chromatograms were checked individually for base-calling errors on FinchTV viewer (Geospiza Inc., Seattle, WA, USA). Obtained sequences (750 bp) were subjected to multiple sequence alignment along the reference sequence (Nakao et al. 2000) using Clustal X2 program (Larkin et al. 2007). Aligned data for the sequences were exported to DnaSP 6 program (Rozas et al. 2017) in FASTA format to compute polymorphism (number of mutations, haplotype number, and frequency) among the population under study. Haplotypic network was inferred using PopArt software (Leigh and Bryant 2015). Population genetics analysis was done using Arlequin package 3.5 (Excoffier and Lischer, 2010) to estimate nucleotide and haplotype diversities, neutrality indices (Tajima's D and Fu's Fs) among the Sardinian intermediate hosts. A pairwise fixation index (Fst) among the E. granulosus s.s. populations from Sardinia and the other Mediterannean countries (Italy, Turkey, France, 
Spain, Tunisia, and Algeria) was computed to understand the degree of gene flow among these countries (Boufana et al. 2014, 2015a, 2015b; Kinkar et al. 2016, 2017, 2018b; Laatamna et al. 2019; Bonelli et al. 2020; Table S1). Pairwise divergence in each intermediate host population from Sardinia and maximum likelihood phylogenetic analysis were done by MEGA X software (Kumar et al. 2018). Reference sequences used to compute inter and intraspecific phylogenies were taken from Nakao et al. (2000) for $E$. granulosus s.s. (G1), Nakao et al. (2002) for Echinococcus multilocularis, Nakao et al. (2003) for Taenia solium, Nakao et al. (2007) for E. multilocularis, Echinococcus vogeli, Echinococcus oligarthra, E. canadensis (G6 and G7), and Bonelli et al. (2020) for E. granulosus s.s. (G3).

\section{Results}

Successful amplification was achieved for 69 isolates out of 70 collected specimens; one goat isolate did not yield readable sequence and was, therefore, excluded from the molecular analysis. Obtained sequences were aligned with the reference sequence (Nakao et al. 2000) for genotypic and haplotypic assessments. G1 genotype was the predominant genotype appearing in 55 isolates $(79.71 \%)$ belonging to sheep $(n=41,78.84 \%)$, cattle $(n=9,81.81 \%)$, pigs $(n=3$, $75.00 \%)$, and goats $(n=2,100 \%)$. G3 genotype was detected in 13 isolates originating from sheep $(n=11,21.15 \%)$, pigs $(n=1,25.00 \%)$, and cattle $(n=1,9.10 \%)$ (Fig. 1).

A total of 22 mutations were identified in 69 sequences at 22 segregating loci, of which $11(50 \%)$ were parsimony informative. Among the total 22 nucleotide substitutions, 9 were non-synonymous $(40.90 \%)$ and 13 were synonymous $(59.10 \%)$. No indels or gaps were detected (Table 1). The nucleotide substitutions at the polymorphic loci were manifested by more transitions $(n=18)$ than the transversions $(n=3)$. A maximum likelihood (ML) tree was constructed for phylogenetic resolution of the obtained sequences which clearly positioned the obtained sequences among E. granulosus s.s. (G1 and G3 strains) reference sequences (Fig. 2). Degree of genetic divergence between the sequences was represented by horizontal branch lengths on the tree.

Haplotypic composition of the E. granulosus s.s. population demonstrated the occurrence of 22 haplotypes, among which 17 haplotypes (77.27\%) grouped with G1 genotype whereas 4 microvariants (18.18\%) were ascribed to G3 strain. A statistical parsimony network was constructed to discern genealogical relationship among the haplotypes which exhibited a star like configuration (Fig. 3). Clustered around a dominant haplotype, EgSar1, the network topology confirmed the presence of a common haplotype (33.33\%) among Sardinian E. granulosus s.s. population (Table 2). The nucleotide sequence of EGSar1 was $100 \%$ identical
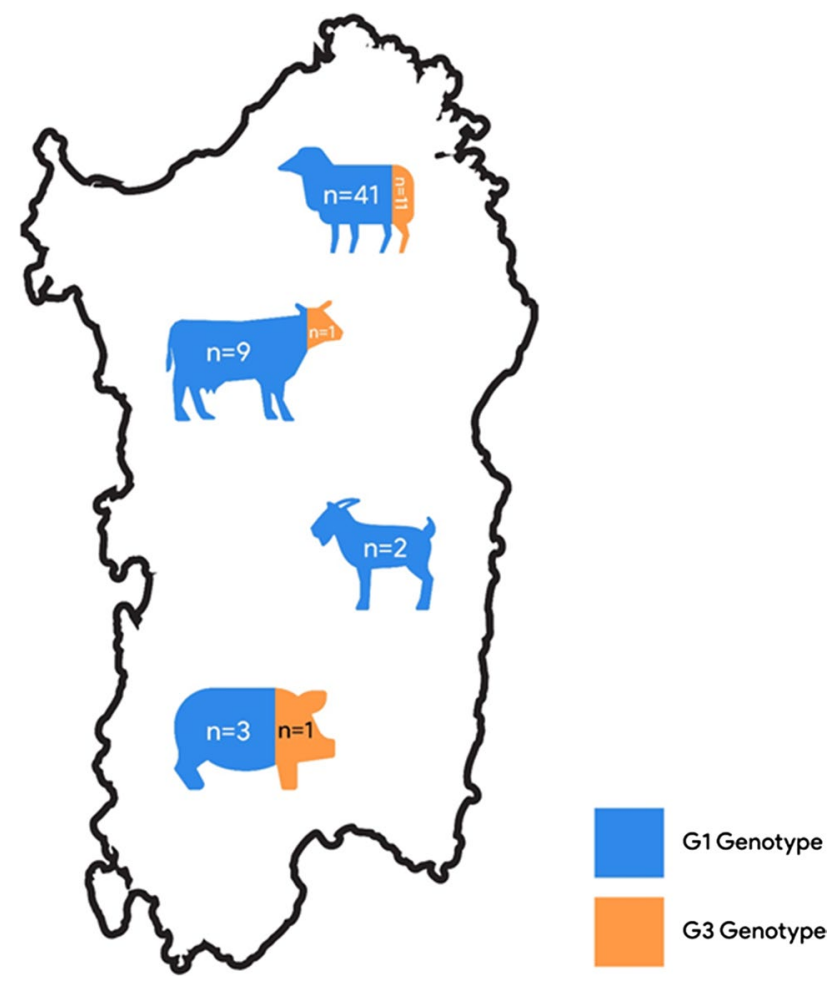

Fig. 1 Map of Sardinia stating prevalence of G1 and G3 genotypes among the examined isolates $(n=69)$ form different intermediate hosts. Colors are indicating frequency of each genotype in the intermediate hosts

to the dominant haplotype reported in earlier studies from Sardinia (Bonelli et al. 2020), Italy (Sgroi et al. 2019), UK (Boufana et al. 2015c), Tunisia (Boufana et al. 2014), and China (Ma et al. 2012). Fourteen unique G1 haplotypes were identified, of which 12 were singleton variants mainly characterized from sheep $(n=9)$. None of the goat isolates harbored the dominant G1 haplotype. The second most common haplotype, EgSar7 (15.94\%), shared 100\% similarity with microvariant reported earlier in Tunisia (Boufana et al. 2014). G3 haplogroup was only represented by 4 haplotypes which formed a small cluster separated by 2 or 3 mutational steps from the common G3 haplotype, EgSar3 (7.24\%). G3 haplotypes displayed low nucleotide polymorphism and were identified from sheep, cattle, and pig isolates only. One haplotype, EgSar14, identified from cattle was shared among both $\mathrm{G} 1$ and $\mathrm{G} 3$ haplogroups with one mutational difference from both genotypes.

Substantial variation in the sequences accounted for further population genetics analysis on the E. granulosus s.s. isolates from the Sardinian intermediate hosts. Overall high haplotype diversity within all host species $(0.8555 \pm 0.033)$ was observed along with low nucleotide diversity $(0.00281 \pm 0.00030)$, a feature characteristic of expanding populations. High haplotype diversity was demonstrated 
Table 1 Number, type of mutations, and pairwise divergence among $E$ granulosus s.s. population of Sardinia

\begin{tabular}{llllll}
\hline Host animals & $\begin{array}{l}\text { No. of sequences } \\
\text { analyzed }\end{array}$ & $\begin{array}{l}\text { No. of } \\
\text { mutations }\end{array}$ & $\begin{array}{l}\text { Transitions/ } \\
\text { transversions }\end{array}$ & $\begin{array}{l}\text { No. of polymorphic/ } \\
\text { segregating sites }\end{array}$ & $\begin{array}{l}\text { Pairwise } \\
\text { divergence } \\
(\%)\end{array}$ \\
\hline Sheep & 52 & 20 & $16 / 4$ & 20 & 0.29 \\
Cattle & 11 & 8 & $7 / 1$ & 8 & 0.24 \\
Pig & 4 & 4 & $3 / 1$ & 4 & 0.27 \\
Goat & 2 & 0 & $0 / 0$ & 0 & 0.00 \\
Overall & 69 & 22 & $18 / 3$ & 22 & $0.28^{*}$ \\
\hline
\end{tabular}

*Mean value for cattle $(0.8727 \pm 0.0891)$, sheep $(0.8620 \pm 0.0363)$, and pig $(0.8333 \pm 0.2224)$ isolates. Nucleotide diversity values were quite low ranging from $0.002424 \pm 0.001717$ (cattle) to $0.002958 \pm 0.001856$ (sheep). Both haplotype and nucleotide diversities were zero for the goat isolates because of occurrence of a single haplotype and limited sample size $(n=2)$. Tests of neutrality, computed to delineate the demographic characteristics of populations, indicated a negative bias. Neutrality indices were negative $(D=-1.72040$, Fs $=-15.600$ ) for the whole population. Tajima's $D$ value was only significantly negative for sheep population $(-1.64449, p<0.05)$ whereas Fu's Fs statistic was significantly negative for sheep $(-10.53163, p<0.05)$ and cattle $(-3.32340, p<0.05)$ populations (Table 3 ). Tajima's $D$ is based on polymorphism among the alleles and the significant values indicate an excess of rare nucleotide site variants in comparison to what is expected under neutral model of evolution. The Fu's Fs statistic, on the other hand, is based on the variant alleles within the population and the significant values signify population expansion and occurrence of rare haplotypes compared to what would be expected under neutrality. To understand gene flow patterns for E. granulosus s.s., a pairwise Fst was calculated for different regional populations of the Mediterranean region and Sardinia. Low Fst values were exhibited for $E$. granulosus s.s. populations of Sardinia and Italy $(-0.01193)$ whereas highest Fst value was observed for Sardinia and Tunisia $(0.07382, p<0.05)$ (Table 4).

\section{Discussion}

Genetic diversity and population structure analysis of $E$. granulosus s.s. were evaluated on the basis of partial mitochondrial coxl gene. The coxl genotyping confirmed the presence of E. granulosus s.s. in all livestock species. Considering the widespread presence, it could be emphasized that $E$. granulosus s.s. was the primary species in disease etiology among the domestic ungulates of Sardinia. Molecular characterization revealed the existence of shared and unique haplotypes among the host animals indicating circulation and cross-transmission of E. granulosus s.s. between these intermediate hosts and the role of these ungulates in perpetuation of domestic cycle. E. granulosus s.s. is maintained in synanthropic cycles involving domestic herbivores which potentially harbor fertile cysts and maintain infection reservoir for dogs and, therefore, humans (Boufana et al. 2014).

G1 has cosmopolitan distribution (Kinkar et al. 2018c) and is regarded as the most prevalent strain across Mediterranean region (Bonelli et al. 2018), Europe (Casulli et al. 2012; Kinkar et al. 2016), China (Yanagida et al. 2012), South America (Laurimäe et al. 2016; Rojas et al. 2017), and Africa (Boufana et al. 2014) among all intermediate hosts including humans. Even though genotypes G1 and G3 are grouped together as E. granulosus s.s., distinctiveness among these strains is present at mitochondrial level (Kinkar et al. 2017; 2018a), but not when the nuclear genes are analyzed (Kinkar et al. 2017). G3 strain, also named as buffalo strain (Bowles et al. 1992), is less prevalent globally but commonly occurs in areas with large buffalo populations like Italy (Capuano et al. 2006; Busi et al. 2007), India (Sharma et al. 2013) and Pakistan (Mehmood et al. 2020; Muqaddas et al. 2020). Sharing common evolutionary trajectory, members of E. granulosus s.s. (G1 and G3 strains) occupy similar ecological niches around the globe but marked differences in prevalence of these genotypes could be linked to paleo-zoogeographic events and parasite's life history. Phylogeographic routes based on Bayesian model point towards probable transmission of G3 from Asia into Europe (Kinkar et al. 2018a).

Twenty-two (22) haplotypes of G1-G3 complex were obtained in current molecular analysis forming two haplogroups. G1 was found as the principal strain (79.71\%) infecting all host types. A multiple star-like configuration was observed among the E. granulosus s.s. isolates originating from sheep, cattle, pigs, and goats. Sheep harbored maximum number of haplotypes $(n=18)$, most probably because $75.36 \%$ isolates were derived from sheep. Alternatively, it could also be argued that sheep were the key hosts in shaping epidemiologic patterns for E. granulosus s.s. at Sardinia. High haplotype diversity $(0.8555 \pm 0.033)$ in congruence with low nucleotide diversity $(0.00281 \pm 0.0030)$ 


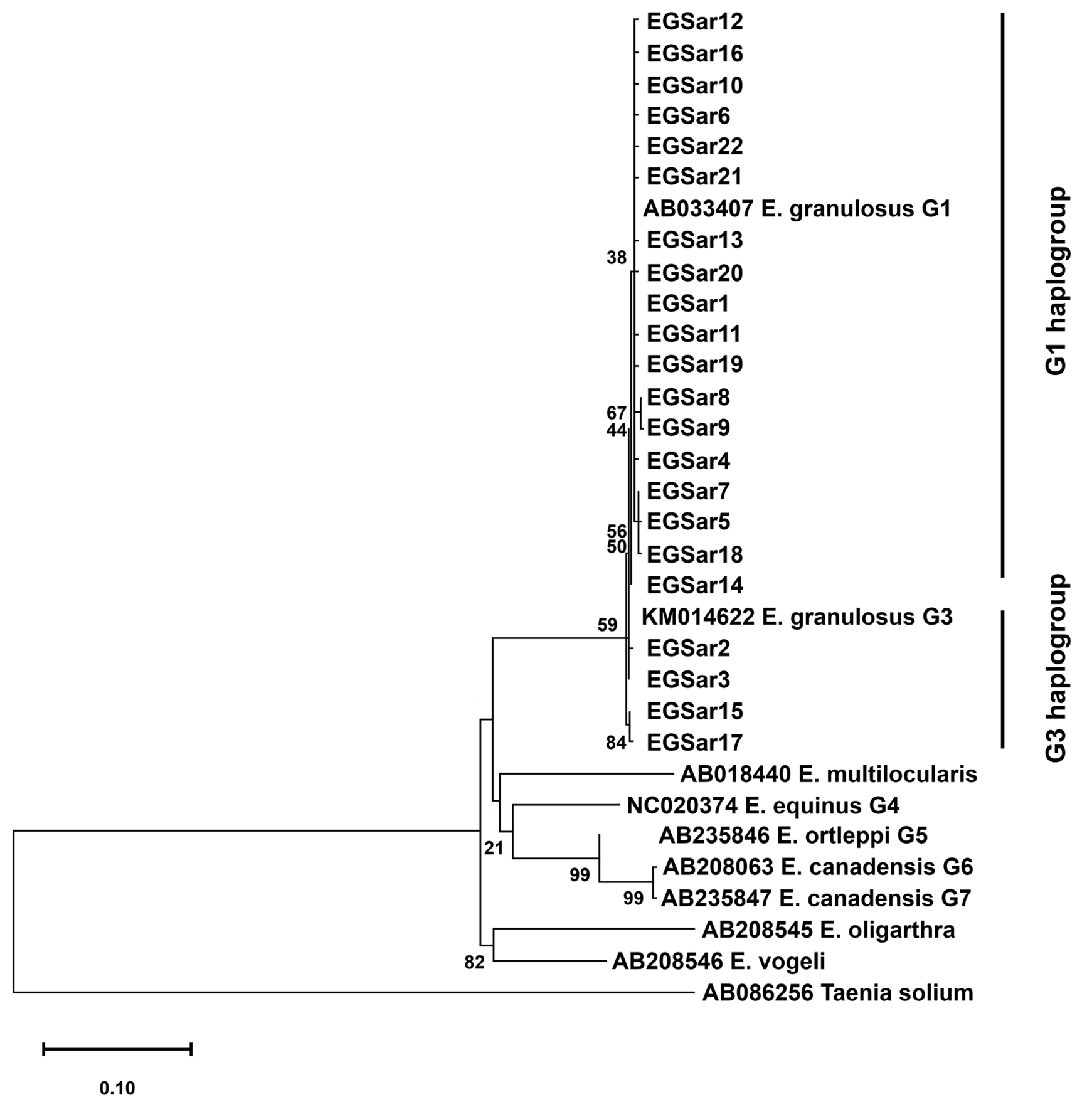

Fig. 2 Phylogenetic tree based on maximum likelihood method indicating positioning of examined sequences with G1 and G3 genotype (E. granulosus s.s.) reference sequences

was manifested for Sardinia, an observation quite similar to other studies displaying genetic diversity and population expansion (Casulli et al. 2012; Yanagida et al. 2012; Boufana et al. 2014; Bonelli et al. 2020).

All subpopulations of E. granulosus s.s. exhibited an overall negative deviation from neutrality ( $D$ and Fu's Fs). Sheep exhibited significantly negative values for these indices whereas cattle had negative values for both components out of which Fu's Fs value was significant. Occurrence of rare polymorphic alleles was suggested by negative statistics and significant values alluded to past bottleneck events as a result of purifying selection and recent demographic expansion. Positive and non-significant bias from neutrality indicates low genetic polymorphism among populations that have undergone bottleneck as evident from lower number of haplotypes in pigs $(n=3)$ which demonstrated positive 
Fig. 3 Haplotypic structure of E. granulosus s.s. genotypes G1 and G3 among domestic ungulates of Sardinia. Vertical lines correspond to the number of mutations between haplotypes and size of the circle indicates frequency of each haplotype (see also Table 2)

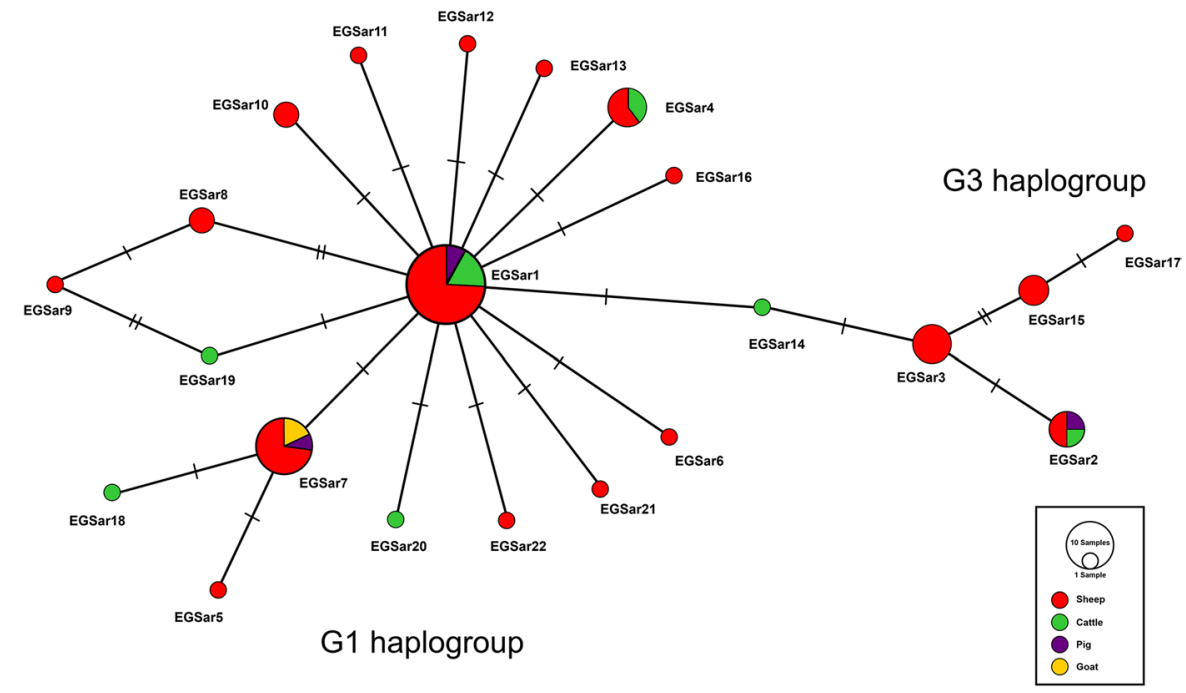

value (0.13353) for Fu's Fs. It is important to mention that this positive outcome could be due to a small sample size which may partially account for detecting low polymorphism in pig specimens. Genetic differentiation estimates between different E. granulosus s.s. populations originating from the Mediterranean countries yielded very low Fst value among
Sardinia and Italy $(-0.01193, p>0.05)$ indicating higher gene flow. While comparing Sardinia with other Mediterranean countries, it was observed that none of the Fst value was negative; however, low Fst value for Spain and Sardinia implied sharing of alleles. Free gene flow because of geographical connectivity and absence of forces that lead to
Table 2 Number of haplotypes and their prevalence in examined host populations

\begin{tabular}{|c|c|c|c|c|c|}
\hline Genotype & Haplotype name & $\begin{array}{l}\text { Number in } \\
\text { the popula- } \\
\text { tion }\end{array}$ & Prevalence (\%) & Host animals & Accession number \\
\hline G1 & EGSar1 & 23 & 33.33 & Sheep, cattle, goat, pig & MW243944 \\
\hline G3 & EGSar2 & 4 & 5.79 & Sheep, cattle, pig & MW243945 \\
\hline G3 & EGSar3 & 5 & 7.24 & Sheep & MW243946 \\
\hline G1 & EGSar4 & 5 & 7.24 & Sheep, cattle & MW243947 \\
\hline G1 & EGSar5 & 1 & 1.45 & Sheep & MW243948 \\
\hline G1 & EGSar6 & 1 & 1.45 & Sheep & MW243949 \\
\hline G1 & EGSar7 & 11 & 15.94 & Sheep, goat, pig & MW243950 \\
\hline G1 & EGSar8 & 2 & 2.89 & Sheep & MW243951 \\
\hline G1 & EGSar9 & 1 & 1.45 & Sheep & MW243952 \\
\hline G1 & EGSar10 & 2 & 2.89 & Sheep & MW243953 \\
\hline G1 & EGSar11 & 1 & 1.45 & Sheep & MW243954 \\
\hline G1 & EGSar12 & 1 & 1.45 & Sheep & MW243955 \\
\hline G1 & EGSar13 & 1 & 1.45 & Sheep & MW243956 \\
\hline G1/G3 & EGSar14 & 1 & 1.45 & Cattle & MW243957 \\
\hline G3 & EGSar15 & 3 & 4.34 & Sheep & MW243958 \\
\hline G1 & EGSar16 & 1 & 1.45 & Sheep & MW243959 \\
\hline G3 & EGSar17 & 1 & 1.45 & Sheep & MW243960 \\
\hline G1 & EGSar18 & 1 & 1.45 & Cattle & MW243961 \\
\hline G1 & EGSar19 & 1 & 1.45 & Cattle & MW243962 \\
\hline G1 & EGSar20 & 1 & 1.45 & Cattle & MW243963 \\
\hline G1 & EGSar21 & 1 & 1.45 & Sheep & MW243964 \\
\hline G1 & EGSar22 & 1 & 1.45 & Sheep & MW243965 \\
\hline
\end{tabular}


Table 3 Diversity and neutrality indices for Echinococcus granulosus s.s. form the intermediate hosts of Sardinia

\begin{tabular}{|c|c|c|c|c|c|c|c|}
\hline & & \multirow[b]{2}{*}{$\begin{array}{l}\text { No. of analyzed } \\
\text { sequences }\end{array}$} & \multirow[b]{2}{*}{$\mathrm{Hn}$} & \multicolumn{2}{|l|}{ Diversity indices } & \multicolumn{2}{|c|}{ Neutrality indices } \\
\hline & & & & $\mathrm{Hd} \pm \mathrm{SD}$ & $\mathrm{Nd} \pm \mathrm{SD}$ & Tajima’s $D$ & Fu's Fs \\
\hline \multirow{5}{*}{$\begin{array}{l}\text { Intermediate } \\
\text { hosts }\end{array}$} & Sheep & 52 & 18 & $0.8620 \pm 0.0363$ & $0.002958 \pm 0.001856$ & $-1.64449 *$ & $-10.53163^{*}$ \\
\hline & Cattle & 11 & 7 & $0.8727 \pm 0.0891$ & $0.002424 \pm 0.001717$ & -1.49340 & $-3.32340 *$ \\
\hline & Pig & 4 & 3 & $0.8333 \pm 0.2224$ & $0.002778 \pm 0.002330$ & -0.78012 & 0.13353 \\
\hline & Goat & 2 & 1 & $0.000 \pm 0.0000$ & $0.0000 \pm 0.00000$ & 0.00000 & 0.00000 \\
\hline & Overall & 69 & 22 & $0.8555 \pm 0.033$ & $0.00281 \pm 0.00030$ & -1.72040 & -15.600 \\
\hline
\end{tabular}

*Significant at $p<0.05$

structuring of the populations is evident from the low Fst values.

To the best of our knowledge, the present manuscript describes for the first time G3 in pigs, with haplotype EGSar2. Echinococcus granulosus s.s. does not primarily target pigs (Paoletti et al. 2019); however, G1 genotype is reported from pigs in Sardinia (Varcasia et al. 2006; Bonelli et al. 2020) and other endemic areas (Casulli et al. 2012; Tigre et al. 2016; Laurimäe et al. 2019; Umhang et al. 2020). Fertile G1 hydatid cysts (69.2\%) have earlier been detected in swine isolates. Pigs and sheep, in comparison with other intermediate hosts, have more defined role in CE epidemiology in Sardinia due to higher cyst fertility rates (Varcasia et al. 2006). Presence of a G3 variant in pig is probably a sign of host overlapping and expansion of host spectrum by G3 genotype; pigs are usually known to harbor G7 genotype (Romig et al. 2015). However, specific future investigations pertaining to swine population of Sardinia are needed to corroborate the role of pigs and their adaptability to different genotypes (G1, G7 and G3) of E. granulosus s.l. (Varcasia et al. 2006).

One haplotype, EGSar14, fell between G1 and G3 genotypes; according to original description of these strains by Bowles et al. (1992) in smaller coxl fragment of 366 bp, one diagnostic position was carrying nucleotide substitution similar to G3 genotype while the other position carried the nucleotide substitution as that of G1 strain. Both of these discriminating sites are present in gene fragment under study at positions 504 and 695 according to the reference sequence given by Nakao et al. (2000). Similar intermediate haplotypes have been identified in other studies at Turkey (Šnábel et al. 2009), Tunisia (Boufana et al. 2014), and China (Ma

Table 4 Pairwise fixation index (Fst) for studied populations of $E$. granulosus s.s. for Sardinia and other Mediterranean countries

\begin{tabular}{llllll}
\hline & Italy & Turkey & Spain & Tunisia & Algeria \\
\hline Sardinia & -0.01193 & $0.06537^{*}$ & 0.03276 & $0.07382^{*}$ & $0.06735^{*}$ \\
\hline
\end{tabular}

*Significant at $p<0.05$ et al. 2015). All such haplotypes are mainly associated with G1 genotype because of diagnostic relevance of second position which entails more significance in strain identification (Šnábel et al. 2009). Recently, nad5 mitochondrial gene is proposed to be a very good gene marker in discriminating G1 and G3 strains (Kinkar et al. 2018b); such haplotypes could be sequenced using nad5 gene marker for correct identification of these isolates.

\section{Conclusion}

The present study provides a compelling evidence on predominant involvement of E. granulosus s.s. in cystic echinococcosis on Sardinia island. Despite being an insular region, Sardinia is considered highly endemic for $\mathrm{CE}$ with sheep-dog cycle as the prominent synanthropic route for the transmission of this parasite. The current study highlighted substantial genetic variation at mitochondrial level (partial coxl) within the sheep and buffalo strains by reaffirming their expansion within the host populations. A G3 haplotype was also identified from pig indicating its incorporation into pig-dog cycle; however, data on cyst fertility is to be correlated with such observations to reach some concrete conclusion. This study also emphasizes the need for refining transmission dynamics for goats and pigs; further studies involving more isolates from goats and pigs must be carried out for identifying their role in disease epidemiology. This study has provided an insight into infective and prominent genotypes cycling within the intermediate hosts and would enable the authorities to devise suitable control strategies for this disease in this hyperendemic region for CE.

Supplementary Information The online version contains supplementary material available at https://doi.org/10.1007/s00436-021-07186-9.

Author contribution Conceptualization, A.V. and N.M.; investigation, G.D., G.J., F.A., C.T.; data curation, M.G.C..; writing-original draft preparation, N.M.; writing—review and editing, M.G.C., A.S., A.V., 
N.M.; All authors have read and agreed to the published version of the manuscript.

Funding Open access funding provided by Università degli Studi di Sassari within the CRUI-CARE Agreement. This research was partially funded by "Fondo di Ateneo per la ricerca 2019" of Prof. Antonio Varcasia and Prof. Antonio Scala, of the University of Sassari, Italy.

Data Availability Not applicable.

Code availability Not applicable.

\section{Declarations}

Ethics approval This study was executed following the recommendations of European Council Directive (86/609/EEC) on the protection of animals.

Consent to participate Not applicable.

Consent for publication Not applicable.

Conflict of interest The authors declare no competing interests.

Open Access This article is licensed under a Creative Commons Attribution 4.0 International License, which permits use, sharing, adaptation, distribution and reproduction in any medium or format, as long as you give appropriate credit to the original author(s) and the source, provide a link to the Creative Commons licence, and indicate if changes were made. The images or other third party material in this article are included in the article's Creative Commons licence, unless indicated otherwise in a credit line to the material. If material is not included in the article's Creative Commons licence and your intended use is not permitted by statutory regulation or exceeds the permitted use, you will need to obtain permission directly from the copyright holder. To view a copy of this licence, visit http://creativecommons.org/licenses/by/4.0/.

\section{References}

Battelli G (2009) Echinococcosis: costs, losses and social consequences of a neglected zoonosis. Vet Res Commun 33(1):47-52. https:// doi.org/10.1007/s11259-009-9247-y

Bonelli P, Masu G, Dei Giudici S, Pintus D, Peruzzu A, Piseddu T, Santucciu C, Cossu A, Demurtas N, Masala, G (2018) Cystic echinococcosis in a domestic cat (Felis catus) in Italy. Parasite 25:25. https://doi.org/10.1051/parasite/2018027

Bonelli P, Dei Giudici S, Peruzzu A, Piseddu T, Santucciu C, Masu G, Mastrandrea S, Delogu ML, Masala G (2020) Genetic diversity of Echinococcus granulosus sensu stricto in Sardinia (Italy). Parasitol Int 77:102120. https://doi.org/10.1016/j.parint.2020.102120

Boufana B, Lahmar S, Rebaï W, Ben Safta Z, Jebabli L, Ammar A, Kachti M, Aouadi S, Craig PS (2014) Genetic variability and haplotypes of Echinococcus isolates from Tunisia. Trans R Soc Trop Med Hyg 108(11):706-714. https://doi.org/10.1093/trstmh/tru138

Boufana B, Said Y, Dhibi M, Craig PS, Lahmar S (2015a) Echinococcus granulosus sensu stricto (ss) from the critically endangered antelope Addax nasomaculatus in Tunisia. Acta Trop 152:112115. https://doi.org/10.1016/j.actatropica.2015.08.015

Boufana B, Lett W, Lahmar S, Griffiths A, Jenkins DJ, Buishi I, Engilez SA, Alrefadi MA, Eljaki AA, Elmestiri FM, Reyes MM,
Ponting S, Al-Hindi A, Torgerson PR, Okamoto M, Craig PS (2015b) Canine echinococcosis: genetic diversity of Echinococcus granulosus sensu stricto (ss) from definitive hosts. J Helminth 89(6):689-698. https://doi.org/10.1017/S0022149X15000395

Boufana B, San Lett W, Lahmar S, Buishi I, Bodell AJ, Varcasia A, Casulli A, Beeching NJ, Campbell F, McManus TM, D. P., Craig PS, (2015c) Echinococcus equinus and Echinococcus granulosus sensu stricto from the United Kingdom: genetic diversity and haplotypic variation. Int J Parasitol 45(2-3):161-166. https://doi.org/ 10.1016/j.ijpara.2014.10.005

Bowles J, Blair D, McManus DP (1992) Genetic variants within the genus Echinococcus identified by mitochondrial DNA sequencing. Mol Biochem Parasitol 54(2):165-173. https://doi.org/10.1016/ 0166-6851(92)90109-W

Budke CM, Deplazes P, Torgerson PR (2006) Global socioeconomic impact of cystic echinococcosis. Emerg Infect Dis 12(2):296. https://doi.org/10.3201/eid1202.050499

Busi M, Šnábel V, Varcasia A, Garippa G, Perrone V, De Liberato C, D'Amelio S (2007) Genetic variation within and between G1 and G3 genotypes of Echinococcus granulosus in Italy revealed by multilocus DNA sequencing. Vet Parasitol 150(1-2):75-83. https://doi.org/10.1016/j.vetpar.2007.09.003

Capuano F, Rinaldi L, Maurelli MP, Perugini AG, Veneziano V, Garippa G, Genchi C, Musella V, Cringoli G (2006) Cystic echinococcosis in water buffaloes: epidemiological survey and molecular evidence of ovine (G1) and buffalo (G3) strains. Vet Parasitol 137(3-4):262-268. https://doi.org/10.1016/j.vetpar. 2006.01.016

Casulli A, Interisano M, Sreter T, Chitimia L, Kirkova Z, La Rosa G, Pozio E (2012) Genetic variability of Echinococcus granulosus sensu stricto in Europe inferred by mitochondrial DNA sequences. Infect Gen Evol 12(2):377-383. https://doi.org/10.1016/j.meegid. 2011.12.014

Conchedda M, Antonelli A, Caddori A, Gabriele F (2010) A retrospective analysis of human cystic echinococcosis in Sardinia (Italy), an endemic Mediterranean region, from 2001 to 2005. Parasitol Int 59(3):454-459. https://doi.org/10.1016/j.parint.2010.06.008

Deplazes P, Rinaldi L, Rojas CA, Torgerson PR, Harandi MF, Romig T, Antolova D, Schurer JM, Lahmar S, Cringoli G, Magambo J, Thompson RC, Jenkins EJ (2017) Global distribution of alveolar and cystic echinococcosis. Adv Parasitol 95:315-493. https://doi. org/10.1016/bs.apar.2016.11.001

Eckert J, Deplazes P (2004) Biological, epidemiological, and clinical aspects of echinococcosis, a zoonosis of increasing concern. Clin Microbiol Rev 17(1):107-135. https://doi.org/10.1128/CMR.17.1. 107-135.2004

Excoffier L, Lischer HE (2010) Arlequin suite ver 3.5: a new series of programs to perform population genetics analyses under Linux and Windows. Mol Ecol Resour 10(3):564-567. https://doi.org/ 10.1111/j.1755-0998.2010.02847.x

Kinkar L, Laurimäe T, Simsek S, Balkaya I, Casulli A, Manfredi MT, Ponce-Gordo F, Varcasia A, Lavikainen A, Gonzalez LM, Rehbein S, van der Giessen J, Sprong H, Saarma U (2016) Highresolution phylogeography of zoonotic tapeworm Echinococcus granulosus sensu stricto genotype G1 with an emphasis on its distribution in Turkey, Italy and Spain. Parasitology 143:1790-1801. https://doi.org/10.1017/S0031182016001530

Kinkar L, Laurimäe T, Sharbatkhori M, Mirhendi H, Kia EB, PonceGordo F, Andresiuk V, Simsek S, Lavikainen A, Irshadullah M, Umhang G, Oudni-M'rad M, Acosta-Jamett G, Rehbein S, Saarma U (2017) New mitogenome and nuclear evidence on the phylogeny and taxonomy of the highly zoonotic tapeworm Echinococcus granulosus sensu stricto. Infect Genet Evol 52:52-58. https://doi. org/10.1016/j.meegid.2017.04.023

Kinkar L, Laurimäe T, Balkaya I, Casulli A, Zait H, Irshadullah M, Sharbatkhori M, Mirhendi H, Rostami-Nejad M, Ponce-Gordo F, 
Rehbein S, Kia EB, Simsek S, Šnábel V, Umhang G, Varcasia A, Saarma U (2018a) Genetic diversity and phylogeography of the elusive, but epidemiologically important Echinococcus granulosus sensu stricto genotype G3. Parasitology 145(12):1613-1622. https://doi.org/10.1017/S0031182018000549

Kinkar L, Laurimäe T, Acosta-Jamett G, Andresiuk V, Balkaya I, Casulli A, Gasser RB, González LM, Haag KL, Zait H, Irshadullah M, Jabbar A, Jenkins DJ, Manfredi MT, Mirhendi H, M'rad S, Rostami-Nejad M, Oudni-M'rad M, Pierangeli NB, Ponce-Gordo F, Rehbein S, Sharbatkhori M, Kia EB, Simsek S, Soriano SV, Sprong H, Šnábel V, Umhang G, Varcasia A, Saarma U (2018b) Distinguishing Echinococcus granulosus sensu stricto genotypes G1 and G3 with confidence: a practical guide. Infect Genet Evol 64:178-184. https://doi.org/10.1016/j.meegid.2018.06.026

Kinkar L, Laurimäe T, Acosta-Jamett G, Andresiuk V, Balkaya I, Casulli A, Gasser RB, van der Giessen J, Gonzalez LM, Haag KL, Zait H, Irshadullah M, Jabbar A, Jenkins DJ, Kia EB, Manfredi MT, Mirhendi H, M'rad S, Rostami Nejad M, Oudni-M'rad M, Pierangeli NB, Ponce-Gordo F, Rehbein S, Sharbatkhori M, Simsek S, Soriano SV, Sprong H, Śnabel V, Umhang G, Varcasia A, Saarma U (2018c) Global phylogeography and genetic diversity of the zoonotic tapeworm Echinococcus granulosus sensu stricto genotype G1. Int J Parasitol 48:729-742. https://doi.org/ 10.1016/j.ijpara.2018.03.006

Kumar S, Stecher G, Li M, Knyaz C, Tamura K (2018) MEGA X: molecular evolutionary genetics analysis across computing platforms. Mol Biol Evol 35(6):1547-1549. https://doi.org/10.1093/ molbev/msy096

Larkin MA, Blackshields G, Brown NP, Chenna R, McGettigan PA, McWilliam H, Valentin F, Wallace IM, Wilm A, Lopez R, Thompson JD, Gibson TJ, Higgins DG (2007) Clustal W and Clustal X version 2.0. Bioinformatics 23(21):2947-2948. https://doi.org/10. 1093/bioinformatics/btm404

Laatamna AE, Ebi D, Brahimi K, Bediaf K, Wassermann M, Souttou K, Romig T (2019) Frequency and genetic diversity of Echinococcus granulosus sensu stricto in sheep and cattle from the steppe region of Djelfa. Algeria Parasitol Res 118(1):89-96. https://doi. org/10.1007/s00436-018-6118-x

Laurimäe T, Kinkar L, Andresiuk V, Haag KL, Ponce-Gordo F, AcostaJamett G, Garate T, Gonzalez LM, Saarma U (2016) Genetic diversity and phylogeography of highly zoonotic Echinococcus granulosus genotype G1 in the Americas (Argentina, Brazil, Chile and Mexico) based on 8279 bp of mtDNA. Infect Genet Evol 45:290-296. https://doi.org/10.1016/j.meegid.2016.09.015

Laurimäe T, Kinkar L, Moks E, Romig T, Omer RA, Casulli A, Umhang G, Bagrade G, Irshadullah M, Sharbatkhori M, Mirhendi H, Ponce-Gordo F, Soriano SV, Varcasia A, Rostami-Nejad M, Andresiuk V, Saarma U (2018) Molecular phylogeny based on six nuclear genes suggests that Echinococcus granulosus sensu lato genotypes G6/G7 and G8/G10 can be regarded as two distinct species. Parasitology 145:1929-1937. https://doi.org/10.1017/S0031 182018000719

Laurimäe T, Kinkar L, Varcasia A, Dessì G, Sgroi G, D’Alessio N, Veneziano V, Saarma U (2019) First detection of zoonotic tapeworm Echinococcus granulosus sensu lato genotype G7 in continental Italy. Parasitol Res 118(7):2193-2201. https://doi.org/10. 1007/s00436-019-06346-2

Leigh JW, Bryant D (2015) POPART: full-feature software for haplotype network construction. Methods Ecol Evol 6(9):1110-1116

Ma J, Wang H, Lin G, Craig PS, Ito A, Cai Z, Zhang T, Han X, Ma X, Zhang J, Liu Y, Zhao Y, Wang Y (2012) Molecular identification of Echinococcus species from eastern and southern Qinghai, China, based on the mitochondrial coxl gene. Parasitol Res 111(1):179-184. https://doi.org/10.1007/s00436-012-2815-z
Ma J, Wang H, Lin G, Zhao F, Li C, Zhang T, Ma X, Zhang Y, Hou Z, Cai H, Liu P, Wang Y (2015) Surveillance of Echinococcus isolates from Qinghai, China. Vet Parasit 207(1-2):44-48

Mehmood N, Muqaddas H, Arshad M, Ullah MI, Khan ZI (2020) Comprehensive study based on mtDNA signature (nad1) providing insights on Echinococcus granulosus s.s. genotypes from Pakistan and potential role of buffalo-dog cycle. Infect Genet Evol 81:104271. https://doi.org/10.1016/j.meegid.2020.104271

Muqaddas H, Mehmood N, Arshad M (2020) Genetic variability and diversity of Echinococcus granulosus sensu lato in human isolates of Pakistan based on cox 1 mt-DNA sequences (366bp). Acta Trop 207:105470. https://doi.org/10.1016/j.actatropica.2020.105470

Nakao M, Sako Y, Yokoyama N, Fukunaga M, Ito A (2000) Mitochondrial genetic code in cestodes. Mol Biochem Parasitol 111(2):415-424. https://doi.org/10.1016/S0166-6851(00)00334-0

Nakao M, Yokoyama N, Sako Y, Fukunaga M, Ito A (2002) The complete mitochondrial DNA sequence of the cestode Echinococcus multilocularis (Cyclophyllidea: Taeniidae). Mitochondrion 1(6):497-509. https://doi.org/10.1016/S1567-7249(02)00040-5

Nakao M, Sako Y, Ito A (2003) The mitochondrial genome of the tapeworm Taenia solium: a finding of the abbreviated stop codon U. J Parasitol 89(3):633-635. https://doi.org/10.1645/ 0022-3395(2003)089[0633:TMGOTT]2.0.CO;2

Nakao M, McManus DP, Schantz PM, Craig PS, Ito A (2007) A molecular phylogeny of the genus Echinococcus inferred from complete mitochondrial genomes. Parasitology 134(5):713. https://doi.org/10.1017/S0031182006001934

Nakao M, Lavikainen A, Yanagida T, Ito A (2013) Phylogenetic systematics of the genus Echinococcus (Cestoda: Taeniidae). Int J Parasitol 43(12-13):1017-1029. https://doi.org/10.1016/j. ijpara.2013.06.002

Nakao M, Lavikainen A, Hoberg EP (2015) Is Echinococcus intermedius a valid species? Trends Parasitol 31:342-343. https:// doi.org/10.1016/j.pt.2015.04.012

Paoletti B, Della Salda L, Di Cesare A, Iorio R, Vergara A, Fava C, Olivastri A, Dessì G, Scala A, Varcasia A (2019) Epidemiological survey on cystic echinococcosis in wild boar from Central Italy. Parasitol Res 118(1):43-46. https://doi.org/10. 1007/s00436-018-6112-3

Rojas CAA, Ebi D, Paredes R, Acosta-Jamett G, Urriola N, Roa JC, Manterola C, Cortes S, Romig T, Scheerlinck JP, Lightowlers MW (2017) High intraspecific variability of Echinococcus granulosus sensu stricto in Chile. Parasitol Int 66(2):112-115. https://doi.org/10.1016/j.parint.2016.12.001

Romig T, Ebi D, Wassermann M (2015) Taxonomy and molecular epidemiology of Echinococcus granulosus sensu lato. Vet Parasitol 213(3-4):76-84. https://doi.org/10.1016/j.vetpar.2015.07.035

Rozas J, Ferrer-Mata A, Sánchez-DelBarrio JC, Guirao-Rico S, Librado P, Ramos-Onsins SE, Sánchez-Gracia A (2017) DnaSP 6: DNA sequence polymorphism analysis of large data sets. Mol Biol Evol 34(12):3299-3302. https://doi.org/10.1093/molbev/msx248

Saarma U, Jõgisalu I, Moks E, Varcasia A, Lavikainen A, Oksanen A, Simsek S, Andresiuk V, Denegri G, González LM, Ferrer E, Gárate T, Rinaldi L, Maravilla P (2009) A novel phylogeny for the genus Echinococcus, based on nuclear data, challenges relationships based on mitochondrial evidence. Parasitology 136(3):317. https://doi.org/10.1017/S0031182008005453

Scala A, Garippa G, Varcasia A, Tranquillo VM, Genchi C (2006) Cystic echinococcosis in slaughtered sheep in Sardinia (Italy). Vet Parasitol 135(1):33-38. https://doi.org/10.1016/j.vetpar.2005. 08.006

Sgroi G, Varcasia A, Dessi G, D’Alessio N, Tamponi C, Saarma U, Laurimäe T, Kinkar L, Santoro M, Caputo V, Sarnelli P, Fusco G, Varuzza P, Fioretti A, Scala A, Veneziano V (2019) Cystic echinococcosis in wild boars (Sus scrofa) from southern Italy: epidemiological survey and molecular characterization. Int $\mathbf{J}$ 
Parasitol Parasites Wildl 9:305-311. https://doi.org/10.1016/j. ijppaw.2019.04.013

Sharbatkhori M, Harandi MF, Mirhendi H, Hajialilo E (2011) Kia EB (2011) Sequence analysis of coxl and nadl genes in Echinococcus granulosus G3 genotype in camels (Camelus dromedarius) from central Iran. Parasitol Res 108:521-527. https://doi.org/10.1007/ s00436-010-2092-7

Sharma M, Sehgal R, Fomda BA, Malhotra A, Malla N (2013) Molecular characterization of Echinococcus granulosus cysts in north Indian patients: identification of G1, G3, G5 and G6 genotypes. PLoS Negl Trop Dis 7(6):e2262. https://doi.org/10.1371/journal. pntd.0002262

Šnábel V, Altintas N, D'amelio S, Nakao M, Romig T, Yolasigmaz A, Gunes K, Turk M, Busi M, Hüttner M, Ševcová D, Ito A, Altintas N, Dubinský P (2009) Cystic echinococcosis in Turkey: genetic variability and first record of the pig strain (G7) in the country. Parasitol Res 105(1):145. https://doi.org/10.1007/ s00436-009-1376-2

Thompson RCA (2017) Biology and systematics of Echinococcus. Adv Parasitology 95:65-109. https://doi.org/10.1016/bs.apar.2016.07. 001

Tigre W, Deresa B, Haile A, Gabriël S, Victor B, Van Pelt J, Devleesschauwer B, Vercruysse J, Dorny P (2016) Molecular characterization of Echinococcus granulosus s.l. cysts from cattle, camels, goats and pigs in Ethiopia. Vet Parasitol 215:17-21. https://doi. org/10.1016/j.vetpar.2015.10.022

Umhang G, Richomme C, Bastid V, Boucher JM, de Garam CP, ItiéHafez S, Danan C, Boué F (2020) National survey and molecular diagnosis of Echinococcus granulosus sensu lato in livestock in France, 2012. Parasitology 147(6):667-672. https://doi.org/10. 1017/S0031182020000190

Varcasia A, Canu S, Lightowlers MW, Scala A, Garippa G (2006) Molecular characterization of Echinococcus granulosus strains in Sardinia. Parasitol Res 98(3):273-277. https://doi.org/10.1007/ s00436-005-0059-x

Varcasia A, Piseddu T, Pipia AP, Schianchi G, Marongiu A, Petruzzi V, Scala A, Garippa G (2008) Epidemiological and biomolecular updates on cystic echinococcosis in pigs and wild boars of Sardinia (Italy). Lucr Stiintifice Med Veterinara 41:385-387

Varcasia A, Dessì G, Lattanzio S, Marongiu D, Cuccuru C, Carta S, Meloni MP, Tamponi C, Scala A (2020) Cystic echinococcosis in the endemic island of Sardinia (Italy): has something changed? Parasitol Res 119(7):2207-2215. https://doi.org/10. 1007/s00436-020-06717-0

Yanagida T, Mohammadzadeh T, Kamhawi S, Nakao M, Sadjjadi SM, Hijjawi N, Abdel-Hafez SK, Sako Y, Okamoto M, Ito A (2012) Genetic polymorphisms of Echinococcus granulosus sensu stricto in the Middle East. Parasitol Int 61(4):599-603. https://doi.org/ 10.1016/j.parint.2012.05.014

Publisher's note Springer Nature remains neutral with regard to jurisdictional claims in published maps and institutional affiliations. 